\title{
A Prospective Study of the Association between Arterial Blood Gases Disturbances, Serum Lactate Level and the Prognosis of Acutely Poisoned Patient in Ain-Shams Poison Control Center
}

\author{
Maha A. Hilal ${ }^{1}$, Mona Elkotp Moussa ${ }^{2}$, Alaa Mohamed Abd Elgwad*1, Reda M. Elsayed ${ }^{1}$
}

${ }^{1}$ Department of Forensic Medicine \& Clinical Toxicology, Faculty of Medicine, Sohag University, Sohag, Egypt. ${ }^{2}$ Department of Forensic Medicine \& Clinical Toxicology, Faculty of Medicine, Ain Shams University, Cairo, Egypt. *Corresponding author: Alaa Mohamed Abd Elgwad, Mobile: (+20) 01095929540, E-Mail: Alaa.abdelgwad18@yahoo.com

\begin{abstract}
Background: Analysis of blood gases and acid-base status is an essential tool in assessment of ill patients in the emergency setting. However, the role of acid-base disturbance on survival of acutely poisoned patients has not been thoroughly investigated.

Objective: To evaluate the role of arterial blood gases (ABG) and serum lactate level for early detection of the severity of toxicity and prediction of death in acutely poisoned patients.

Patients and methods: The current study is a prospective study that was done on 100 of acutely poisoned patients by drugs and toxins with acid base disturbances effect. They were admitted to Ain-Shams Poison Control Center, during the period from January 2019 to the end of December 2019.

Results: Results of the current study revealed that $47.8 \%$ of dead patients suffered from metabolic acidosis and respiratory acidosis, $30.4 \%$ of them, were with metabolic acidosis, $13 \%$ of them were with respiratory acidosis, and $8.7 \%$ of them, were with metabolic acidosis and respiratory alkalosis. According to ROC curve analysis serum lactate level can be used as a predictor of mortality as serum lactate level with cut off $>1.45$ had sensitivity of $91.3 \%$, specificity $29.8 \%$ and NPV $93.6 \%$ with excellent diagnostic characteristic ( accuracy rate $84.6 \%$ ).

Conclusion: The study concluded that $\mathrm{ABG}$ and serum lactate level can be used as simple predictor tools of the severity of toxicity and prediction of death in acutely poisoned patients.
\end{abstract}

Keywords: Arterial blood gases disturbances, Serum lactate, Acutely poisoned.

\section{INTRODUCTION}

Analysis of blood gases and acid-base status is an essential tool in assessment of ill patients in the emergency setting ${ }^{(\mathbf{1})}$.

Lactate is a metabolic byproduct of anaerobic metabolism and therefore is produced by most tissues in the human body. Lactate is rapidly cleared by the liver with some additional clearance by the kidneys under normal conditions. Elevated concentrations of serum lactate occur in conditions that cause tissue hypoxia/hypoperfusion (type A) as well as other pathophysiologic conditions (type B) not related to tissue hypoxia ${ }^{(2)}$.

Blood lactate levels have been used as a prognostic factor in critically ill patients. Lactate has also been studied for the prognosis of patients with poisoning from metformin, acetaminophen, beta blockers, carbon monoxide, cyanide and paraquat ${ }^{(3)}$. Regardless of the etiology of elevated serum lactate concentration, it is a useful prognostic indicator in a variety of clinical circumstances. However, there are conflicting data about the utility of lactate specifically in the setting of acute drug overdose, which leaves the prognostic indicator utility of lactate an open question (4).

Under anaerobic conditions, lactate is an end product of glycolysis and feeds into the Cori cycle as a substrate for gluconeogenesis. Hyperlactatemia is an elevated lactate concentration, and lactic acidosis is an elevated lactate concentration accompanied by a decrease in blood $\mathrm{pH}^{(\mathbf{5}, \mathbf{6})}$.

Elevated concentrations of serum lactate occur in conditions that cause tissue hypoxia/hypoperfusion (type A) as well as other pathophysiologic conditions (type B) not related to tissue hypoxia ${ }^{(2)}$.

The present study aimed to evaluate the role of Arterial blood gases (ABG) and serum lactate level for early detection of the severity of toxicity and prediction of death in acutely poisoned patients.

\section{PATIENTS AND METHODS}

This prospective study was conducted on 100 of acutely poisoned patients by drugs and toxins with acid base disturbances effect. They were admitted to AinShams Poison Control Center, during the period from January 2019 to the end of December 2019.

\section{Inclusion criteria:}

Acute toxicity with toxins that cause ABG disturbances effect like opioids, sedatives, pesticides, alcohols, stimulants, barbiturates, antidepressant, metformin, acetaminophen, theophylline, antipsychotics, antiepileptics ... etc. The type of toxin was determined according to the history given by the patient him/herself if he/she is conscious on admission and from clinical signs and investigations. If the patient is unconscious, the history was taken from the relatives. 


\section{Exclusion criteria:}

Patients with on-arrival or pre-arrival cardiopulmonary arrest and subjected to CPR.

\section{Ethical conditions:}

An approval of the study was obtained from Sohag University Academic and Ethical Committee. All patients or relatives signed a written informed consent before participation. This work has been carried out in accordance with The Code of Ethics of the World Medical Association (Declaration of Helsinki) for studies involving humans.

\section{Methods:}

A special sheet designed for the study to record the history, examination and investigations were done for each patient.

Data recorded included the following:

1-Socio demographic data.

2-Full history included history of present illness, and past history.

3- Clinical examination:

A-General examination:

- Scoring scales: GCS: GCS from (3-15 points) was determined based on three components: Eyes, verbal and motor.

- Vital Data: Pulse (heart rate), blood pressure, temperature, and respiratory rate.

- Complexions.

- Skin examination.

- Pupil examination.

B-Local examination: Chest, cardiac, abdominal, and neurological examination.

\section{4-Investigations:}

They were performed according to specific requirements of each patient. For full assessment of patients' conditions, the following tests were frequently performed:

\section{A- Random blood sugar level (RBS).}

B- Kidney function profile (Serum urea and creatinine) by Beckman Coulter AU480 Clinical Chemistry System.

C- Liver biochemistry aspartate aminotransferase (AST) and alanine aminotransferase (ALT) by Beckman Coulter AU480 Clinical Chemistry System.

D- Electrocardiography: ECG parameters from the first ECG taken on ICU or ED admission were recorded from all patients as rate, rhythm, QT and PR intervals, QRS complex, ST segment abnormality, and $\mathrm{T}$ wave changes.

\section{5-Specific laboratory investigations:}

A- Blood Gas Analysis: They were analyzed using MEDICA Easy stat for assessment of the following $(\mathrm{pH}, \mathrm{PaCO} 2, \mathrm{PaO} 2, \mathrm{SaO} 2$ and $\mathrm{HCO} 3)$.

B- Serum lactate level: Measurement of serum lactates by spectrophotometer.

C- Serum electrolytes (Sodium (Na) and Potassium (k)): Standard solutions were injected in (Blood gas analyzer) and then serum samples were injected in the set so as to determine the serum sodium and potassium levels.

6- Treatment measures: Different treatment measures applied to each patient according to the case include:

- Emergency treatment: endotracheal intubation, oxygen administration and mechanical ventilation,

- Supportive treatment: intravenous fluids, $\mathrm{H}_{2}$ blockers, antibiotics, antiemetic, steroids, dopamine and other vasopressors therapy.

- Decontamination measures: emesis, lavage and activated charcoal.

- Enhanced elimination methods: multiple doseactivated charcoal, alkalinization of urine and dialysis either hemodialysis or peritoneal dialysis.

- Antidotal therapy.

\section{7-Outcome (according to hospital disposition):}

- Site of admission: Emergency department (ED), inpatient wards or ICU.

- Causes of admission to the ICU.

- Duration of hospital stay.

- Outcome: Complete recovery, recovery with complication, discharged against medical advice, transfer to another department, and mortality.

\section{Statistical analysis}

The collected data were coded, processed and analyzed using the SPSS (Statistical Package for Social Sciences) version 22 for Windows ${ }^{\circledR}$ (IBM SPSS Inc, Chicago, IL, USA).

Data were tested for normal distribution using the Shapiro Walk test. Qualitative data were represented as frequencies and relative percentages. Chi square test $\left(\chi^{2}\right)$ to calculate difference between two or more groups of qualitative variables. Quantitative data were expressed as mean \pm SD (Standard deviation). Independent samples t-test was used to compare between two independent groups of normally distributed variables (parametric data). $\mathrm{P}$ value $\leq 0.05$ was considered significant.

\section{RESULTS}

According to age distribution of the studied patients, it was found that half of patients $(50 \%)$ fall in the age group (pediatrics (1-18 years)) and the other half $(50 \%)$ fall in the age group (adults (18-60 years)). 
Gender distribution percentage of the studied-patients showed that poisoned females' percentage $(59 \%)$ was more than males' percentage $(41 \%)$ in the study.

The mode of poisoning in the studied patients was mostly suicide (50\%), accidently exposed (35\%), overdose $(12 \%)$ and the therapeutically poisoned (3\%) (Table 1).

Table (1): Percentage of age, sex and mode of poisoning distribution of the studied patients

\begin{tabular}{|c|c|c|}
\hline Age groups (years) & Number & Percentage (\%) \\
\hline 1-18 years & 50 & $50 \%$ \\
\hline 18-60 years & 50 & $50 \%$ \\
\hline$>60$ years & 0 & $0 \%$ \\
\hline Total & 100 & $100 \%$ \\
\hline $\begin{array}{l}\text { Sex: } \\
\text { Females } \\
\text { Males }\end{array}$ & $\begin{array}{l}59 \\
41\end{array}$ & $\begin{array}{l}59 \% \\
41 \%\end{array}$ \\
\hline $\begin{array}{l}\text { Mode of poisoning: } \\
\text { Accidently } \\
\text { Suicide } \\
\text { Overdose } \\
\text { Therapeutic }\end{array}$ & $\begin{array}{l}35 \\
50 \\
12 \\
3\end{array}$ & $\begin{array}{c}35 \% \\
50 \% \\
12 \% \\
3 \%\end{array}$ \\
\hline
\end{tabular}

The toxic agents that cause acid base disturbances in the studied patients. It was found that major of patients $(15 \%)$ were poisoned by theophylline, $11 \%$ of patients were poisoned by cannabis, $10 \%$ of patients were poisoned by organophosphorus and (9\%) of patients were poisoned by methanol (Table 2).

Table (2): Percentage of the toxic agents among studied patients

\begin{tabular}{|l|c|c|}
\hline \multicolumn{1}{|c|}{ Toxic agent } & Number of cases & \% \\
\hline Co & 4 & 4 \\
\hline Anticonvulsant & 1 & 1 \\
\hline Opioid & 3 & 3 \\
\hline Theophylline & 15 & 15 \\
\hline Zinc phosphide & 8 & 8 \\
\hline B blocker & 3 & 3 \\
\hline Alcohol methanol & 9 & 9 \\
\hline Clozapex & 5 & 5 \\
\hline Alcohol ethanol & 1 & 1 \\
\hline Insulin and tegretol & 1 & 1 \\
\hline Pregaba & 1 & 1 \\
\hline Cidophage & 4 & 4 \\
\hline Zinc phosphide & 2 & 2 \\
\hline Corrosive & 5 & 5 \\
\hline Heroin & 3 & 3 \\
\hline Salicylate & 2 & 2 \\
\hline BDZ & 2 & 2 \\
\hline Carbamate & 4 & 4 \\
\hline Organophosphorus & 10 & 10 \\
\hline Lithium & 2 & 2 \\
\hline Cannabis & 11 & 11 \\
\hline Aluminium phosphide & 4 & 4 \\
\hline Total & 100 & 100 \\
\hline
\end{tabular}

According to the delay time, most of studied patients came with delay time 2 hours (22cases), 13 cases was presented with delay time 3 hours, (12) cases were presented with delay time 4 hours, (10) cases were presented with delay time 1 hour, and only (3) cases were presented with delay time 72 hours (Table 3 ).

Table (3): Percentage of the delay time among studied patients

\begin{tabular}{|c|c|c|}
\hline Delay time & Number of cases & \% \\
\hline 1 hour & 10 & 10 \\
\hline 2 hours & 22 & 22 \\
\hline 3 hours & 13 & 13 \\
\hline 4 hours & 12 & 12 \\
\hline 5 hours & 4 & 4 \\
\hline 6 hours & 7 & 7 \\
\hline 7 hours & 7 & 7 \\
\hline 8 hours & 5 & 5 \\
\hline 9 hours & 4 & 4 \\
\hline $\mathbf{1 0}$ hours & 2 & 2 \\
\hline $\mathbf{1 2}$ hours & 3 & 3 \\
\hline $\mathbf{1 5}$ hours & 1 & 1 \\
\hline $\mathbf{1 8}$ hours & 1 & 1 \\
\hline $\mathbf{2 0}$ hours & 1 & 1 \\
\hline $\mathbf{2 4}$ hours & 2 & 2 \\
\hline $\mathbf{4 8}$ hours & 3 & 3 \\
\hline $\mathbf{7 2}$ hours & 3 & 3 \\
\hline Total & 100 & 100 \\
\hline
\end{tabular}

According to the ABG, 9\% of cases had metabolic acidosis, $22 \%$ had metabolic acidosis and respiratory acidosis, $19 \%$ had normal $\mathrm{pH}$ with metabolic acidosis compensated with respiratory alkalosis, $10 \%$ had respiratory acidosis, 9\% were normal, $6 \%$ had metabolic acidosis and respiratory alkalosis, 5\% had respiratory alkalosis, and no patients with metabolic alkalosis.

Regarding the lactate level, $47 \%$ of cases had normal lactate level, $24 \%$ had mild to moderate elevation of lactate level, $21 \%$ had high lactate level, and $(8 \%)$ have very high lactate level.

Concerning site of admission, 53\% of patients received treatment in in-patient, $45 \%$ of patients were admitted to ICU, and only $2 \%$ received treatment in emergency department (Table 4). 
Table (4): Percentage of arterial blood gases, lactate level and site of admission among all studied patients

\begin{tabular}{|l|c|c|}
\hline \multicolumn{1}{|c|}{ ABG } & $\begin{array}{c}\text { Number } \\
\text { of cases }\end{array}$ & \% \\
\hline Arterial blood gases: & & \\
Metabolic acidosis & & \\
Respiratory acidosis & 29 & 29 \\
Respiratory alkalosis & 10 & 10 \\
Metabolic acidosis with & 5 & 5 \\
respiratory acidosis & 22 & 22 \\
Metabolic acidosis with & 6 & 6 \\
respiratory alkalosis & 9 & 9 \\
Normal & 19 & 19 \\
Normal pH with metabolic & & \\
acidosis and respiratory alkalosis & & \\
\hline Lactate level: & 47 & 47 \\
Normal & 24 & 24 \\
Mild to moderate & 21 & 21 \\
High & 8 & 8 \\
Very high & & \\
\hline Site of admission: & 53 & 53 \\
Inpatient & 45 & 45 \\
ICU & 2 & 2 \\
ED & $\mathbf{1 0 0}$ & $\mathbf{1 0 0}$ \\
\hline
\end{tabular}

According to the relation between site of admission and lactate level, the studied patients with normal lactate level $76.6 \%$ of them were admitted at inpatient, $19.1 \%$ of them were admitted to ICU, and $4.3 \%$ of them were admitted to ED.

The studied patients with mild to moderate elevation of lactate level $58.3 \%$ of them were admitted at inpatient and $41.7 \%$ of them were admitted to ICU.

The studied patients with high elevation of lactate level $95.2 \%$ of them were admitted to ICU and $4.8 \%$ of them were admitted at inpatient. The studied patients with very high elevation of lactate level $75 \%$ of them were admitted to ICU and $25 \%$ of them were admitted at inpatient.

There was very highly significant statistical relationship between the type of acid base disturbances and outcome as $\mathrm{p}$ value was $<0.001$ (Table 5).
Table (5): Chi-Square statistical analysis showing relationship between lactate level and site of admission

\begin{tabular}{|c|c|c|c|c|c|}
\hline \multirow[t]{2}{*}{ Lactate } & & \multicolumn{3}{|c|}{ Site of admission } & \multirow[t]{2}{*}{ Total } \\
\hline & & ER & In-patient & ICU & \\
\hline Normal & $\begin{array}{l}\text { No. } \\
\text { \%within } \\
\text { lactate level }\end{array}$ & $\begin{array}{c}2 \\
4.3 \%\end{array}$ & $\begin{array}{c}36 \\
76.7 \%\end{array}$ & $\begin{array}{c}9 \\
19 \%\end{array}$ & $\begin{array}{c}29 \\
100 \%\end{array}$ \\
\hline $\begin{array}{c}\text { Mild to } \\
\text { moderate }\end{array}$ & $\begin{array}{l}\text { No. } \\
\text { \%within } \\
\text { lactate level }\end{array}$ & $\begin{array}{c}0 \\
0 \%\end{array}$ & $\begin{array}{c}14 \\
58.3 \%\end{array}$ & $\begin{array}{c}10 \\
41.7 \\
\%\end{array}$ & $\begin{array}{c}10 \\
100 \%\end{array}$ \\
\hline High & $\begin{array}{l}\text { No. } \\
\text { \%within } \\
\text { lactate level }\end{array}$ & $\begin{array}{c}0 \\
0 \%\end{array}$ & $\begin{array}{c}1 \\
4.8 \%\end{array}$ & $\begin{array}{c}20 \\
95.2 \\
\% \\
\end{array}$ & $\begin{array}{c}5 \\
100 \%\end{array}$ \\
\hline $\begin{array}{l}\text { Very } \\
\text { high }\end{array}$ & $\begin{array}{l}\text { No. } \\
\text { \%within } \\
\text { lactate level }\end{array}$ & $\begin{array}{c}0 \\
0 \%\end{array}$ & $\begin{array}{c}2 \\
25 \%\end{array}$ & $\begin{array}{c}6 \\
75 \%\end{array}$ & $\begin{array}{c}22 \\
100 \%\end{array}$ \\
\hline \multicolumn{2}{|c|}{ Total } & $2 \%$ & $53 \%$ & $45 \%$ & $100 \%$ \\
\hline \multicolumn{2}{|r|}{$\mathbf{x}^{2}$} & \multicolumn{4}{|c|}{35.608} \\
\hline \multicolumn{2}{|c|}{$P$ value } & \multicolumn{4}{|c|}{0.000} \\
\hline
\end{tabular}

According to the fate and outcome, $43 \%$ of cases showed complete recovery, $27 \%$ of cases had recovery with complications, $23 \%$ of cases died, $7 \%$ of cases left the center against medical advice and no cases escaped or referred (Table 6).

Table (6): Percentage of fate and outcome of the studied patients

\begin{tabular}{|c|l|c|c|}
\hline Survivors & \multicolumn{1}{|c|}{ Outcome } & N & \% \\
\hline \multirow{3}{*}{ Survivors } & Complete recovery & 43 & $43 \%$ \\
\cline { 2 - 4 } & $\begin{array}{l}\text { Recovery with } \\
\text { complications }\end{array}$ & 27 & $27 \%$ \\
\cline { 2 - 4 } & Escaped & 0 & $0 \%$ \\
\cline { 2 - 4 } & $\begin{array}{l}\text { Get out against } \\
\text { medical advice }\end{array}$ & 7 & $7 \%$ \\
\hline $\begin{array}{c}\text { Non } \\
\text { Survivors }\end{array}$ & Died & 23 & $23 \%$ \\
\hline \multicolumn{2}{|c|}{ Total } & $\mathbf{1 0 0}$ & $\mathbf{1 0 0 \%}$ \\
\hline
\end{tabular}

According to the type of acid base disturbances and outcome, dead patients in the study $\mathbf{4 7 . 8 \%}$ of them suffered from metabolic acidosis with respiratory acidosis, $\mathbf{3 0 . 4 \%}$ of them were with metabolic acidosis, $13 \%$ of them were with respiratory acidosis and $\mathbf{8 . 7 \%}$ of them were with metabolic acidosis with respiratory alkalosis. There was very highly significant statistical relationship between the type of acid base disturbances and outcome as $p$ value was $<0.01$ (Table 7). 
Table (7): Chi-Square statistical analysis showing relationship between type of acid base disturbances and outcome

\begin{tabular}{|c|c|c|c|c|}
\hline \multirow[t]{2}{*}{ Type of acid base disturbances } & & \multicolumn{2}{|c|}{ Outcome } & \multirow[t]{2}{*}{ Total } \\
\hline & & Died & Survivors & \\
\hline M. acidosis & $\begin{array}{l}\text { No. } \\
\% \text { within acid base disturbances }\end{array}$ & $\begin{array}{c}7 \\
24.1 \%\end{array}$ & $\begin{array}{c}22 \\
75.9\end{array}$ & $\begin{array}{c}29 \\
100 \%\end{array}$ \\
\hline Resp. acidosis & $\begin{array}{l}\text { No. } \\
\% \text { within acid base disturbances }\end{array}$ & $\begin{array}{c}3 \\
30 \%\end{array}$ & $\begin{array}{c}7 \\
70 \%\end{array}$ & $\begin{array}{c}10 \\
100 \%\end{array}$ \\
\hline Resp. alkalosis & $\begin{array}{l}\text { No. } \\
\% \text { within acid base disturbances }\end{array}$ & $\begin{array}{c}0 \\
0 \%\end{array}$ & $\begin{array}{c}5 \\
100 \%\end{array}$ & $\begin{array}{c}5 \\
100 \%\end{array}$ \\
\hline M.\& Resp. acidosis & $\begin{array}{l}\text { No. } \\
\% \text { within acid base disturbances }\end{array}$ & $\begin{array}{c}11 \\
50 \%\end{array}$ & $\begin{array}{c}11 \\
50 \%\end{array}$ & $\begin{array}{c}22 \\
100 \%\end{array}$ \\
\hline $\begin{array}{c}\text { M.acidosis \& Resp. } \\
\text { alkalosis }\end{array}$ & $\begin{array}{l}\text { No. } \\
\% \text { within acid base disturbances }\end{array}$ & $\begin{array}{c}2 \\
33.3 \%\end{array}$ & $\begin{array}{c}4 \\
66.7 \%\end{array}$ & $\begin{array}{c}6 \\
100 \%\end{array}$ \\
\hline normal & $\begin{array}{l}\text { No. } \\
\% \text { within acid base disturbances }\end{array}$ & $\begin{array}{c}0 \\
0 \%\end{array}$ & $\begin{array}{c}9 \\
100 \%\end{array}$ & $\begin{array}{c}9 \\
100 \%\end{array}$ \\
\hline $\begin{array}{c}\text { Normal PH with M.aidosis } \\
\text { \& Resp. alkalosis }\end{array}$ & $\begin{array}{l}\text { No. } \\
\text { \% within acid base disturbances }\end{array}$ & $0 \%$ & $\begin{array}{c}19 \\
100 \%\end{array}$ & $\begin{array}{c}19 \\
100 \%\end{array}$ \\
\hline \multicolumn{2}{|l|}{ Total } & $23 \%$ & $77 \%$ & $100 \%$ \\
\hline \multicolumn{2}{|c|}{$\mathbf{x}^{2}$} & \multicolumn{3}{|c|}{19.573} \\
\hline \multicolumn{2}{|c|}{$P$ value } & \multicolumn{3}{|c|}{.003} \\
\hline
\end{tabular}

${ }^{*} \mathrm{P}<0.05$ (significant) ${ }^{* *} \mathrm{P}<.01$ (highly significant) ${ }^{* * * *} \mathrm{P}<.001$ (very highly significant)

The GCS and outcome, $26.1 \%$ of the dead studied patients were with GCS, $17.4 \%$ of them were with GCS $4,13 \%$ of them were with GCS 15 and 8.7\% of them were with GCS 5, 7,11,12, and 13. There was very high significant statistical relationship between GCS and outcome as p value was < 0.001 (table 8).

Table (8): Chi-Square statistical analysis showing relationship between GCS and outcome

\begin{tabular}{|c|c|c|c|c|}
\hline \multirow[t]{2}{*}{ GCS } & & \multicolumn{2}{|c|}{ Outcome } & \multirow[t]{2}{*}{ Total } \\
\hline & & Died & Survivors & \\
\hline 3 & $\begin{array}{l}\text { No. } \\
\text { \%within GCS }\end{array}$ & $\begin{array}{c}6 \\
85.7 \%\end{array}$ & $\begin{array}{c}1 \\
14.3 \%\end{array}$ & $\begin{array}{c}7 \\
100 \%\end{array}$ \\
\hline 4 & $\begin{array}{l}\text { No. } \\
\text { \%within GCS }\end{array}$ & $\begin{array}{c}4 \\
100 \%\end{array}$ & $\begin{array}{c}0 \\
0 \%\end{array}$ & $\begin{array}{c}4 \\
100 \%\end{array}$ \\
\hline 5 & $\begin{array}{l}\text { No. } \\
\text { \%within GCS }\end{array}$ & $\begin{array}{c}2 \\
100 \%\end{array}$ & $\begin{array}{c}0 \\
0 \%\end{array}$ & $\begin{array}{c}2 \\
100 \% \\
\end{array}$ \\
\hline 6 & $\begin{array}{l}\text { No. } \\
\text { \%within GCS }\end{array}$ & $\begin{array}{c}0 \\
0 \%\end{array}$ & $\begin{array}{c}3 \\
100 \%\end{array}$ & $\begin{array}{c}3 \\
100 \%\end{array}$ \\
\hline 7 & $\begin{array}{l}\text { No. } \\
\text { \%within GCS }\end{array}$ & $\begin{array}{c}2 \\
33.3 \%\end{array}$ & $\begin{array}{c}4 \\
66.7 \%\end{array}$ & $\begin{array}{c}6 \\
100 \%\end{array}$ \\
\hline 10 & $\begin{array}{l}\text { No. } \\
\text { \%within GCS }\end{array}$ & $\begin{array}{c}0 \\
0 \%\end{array}$ & $\begin{array}{c}1 \\
100 \%\end{array}$ & $\begin{array}{c}1 \\
100 \%\end{array}$ \\
\hline 11 & $\begin{array}{l}\text { No. } \\
\text { \%within GCS }\end{array}$ & $\begin{array}{c}2 \\
66.7 \%\end{array}$ & $\begin{array}{c}1 \\
33.3 \%\end{array}$ & $\begin{array}{c}3 \\
100 \%\end{array}$ \\
\hline 12 & $\begin{array}{l}\text { No. } \\
\text { \%within GCS }\end{array}$ & $\begin{array}{c}2 \\
50 \%\end{array}$ & $\begin{array}{c}2 \\
50 \%\end{array}$ & $\begin{array}{c}4 \\
100 \%\end{array}$ \\
\hline 13 & $\begin{array}{l}\text { No. } \\
\text { \%within GCS }\end{array}$ & $\begin{array}{c}2 \\
12.5 \%\end{array}$ & $\begin{array}{c}14 \\
87.5\end{array}$ & $\begin{array}{c}16 \\
100 \%\end{array}$ \\
\hline 14 & $\begin{array}{l}\text { No. } \\
\% \text { within GCS }\end{array}$ & $\begin{array}{c}0 \\
0 \%\end{array}$ & $\begin{array}{c}2 \\
100 \%\end{array}$ & $\begin{array}{c}2 \\
100 \% \\
\end{array}$ \\
\hline 15 & $\begin{array}{l}\text { No. } \\
\text { \%within GCS }\end{array}$ & $\begin{array}{c}3 \\
5.8 \%\end{array}$ & $\begin{array}{c}49 \\
92 \%\end{array}$ & $\begin{array}{c}52 \\
100 \%\end{array}$ \\
\hline & Total & $23 \%$ & $77 \%$ & $100 \%$ \\
\hline & $x^{2}$ & & 52.377 & \\
\hline & P value & & .0001 & \\
\hline
\end{tabular}

Independent t-test showing very highly significant difference between lactate levels in died patients and survivors as the mean in died was $7.98 \mathrm{mmol} / \mathrm{L}$, while in survivors was $2.65 \mathrm{mmol} / \mathrm{L}$ (Table 9). 
Table (9): Independent t-test statistical analysis of serum lactate level among died patients and survivors

\begin{tabular}{|c|c|c|c|c|c|}
\hline \multicolumn{2}{|c|}{ Variable } & Died patients & Survivors & \multicolumn{2}{c|}{ Independent t-test } \\
\cline { 2 - 6 } & $\mathrm{N}=\mathbf{2 3}$ & $\mathrm{N}=77$ & $\mathrm{~T}$ & p-value \\
\hline $\begin{array}{c}\text { Lactate } \\
(\mathrm{mmol} / \mathrm{L})\end{array}$ & Mean \pm SD & $\mathbf{7 . 9 8} \pm \mathbf{1 . 3 2}$ & $\mathbf{2 . 6 5} \pm \mathbf{0 . 2 9}$ & $\mathbf{7 . 1 8}$ & $\mathbf{0 . 0 0 1}$ \\
\hline
\end{tabular}

Serum lactate level had sensitivity of $91.3 \%$ as 20 patients had abnormal serum lactate level among 23 died. While, specificity was $29.8 \%$ as 44 patients had normal serum lactate level among 77 survivors. Positive predictive value (PPV) of lactate was $37.7 \%$ as 20 patients died from total 53 had abnormal lactate level and negative predictive value (NPV) was $93.6 \%$ as 44 patients survived from total 47 had normal lactate level (Table 10).

Table (10): Sensitivity, specificity and accuracy rate of serum lactate level as predictors of mortality in the current study

\begin{tabular}{|l|c|c|c|c|c|c|c|c|}
\hline Variable & $\begin{array}{c}\text { Cut } \\
\text { off } \\
\text { point }\end{array}$ & $\begin{array}{c}\text { AUC } \\
\text { (Area } \\
\text { under } \\
\text { the } \\
\text { curve) }\end{array}$ & $\begin{array}{c}\text { p- } \\
\text { value }\end{array}$ & $\begin{array}{c}\text { Sensitivity } \\
(\%)\end{array}$ & $\begin{array}{c}\text { Specificity } \\
(\%)\end{array}$ & $\begin{array}{c}\text { PPV (\%) } \\
\text { (Positive } \\
\text { predictive } \\
\text { value) }\end{array}$ & $\begin{array}{c}\text { NPV (\%) } \\
\text { (Negative } \\
\text { predictive } \\
\text { value) }\end{array}$ & $\begin{array}{c}\text { Accuracy } \\
\text { rate }\end{array}$ \\
\hline Lactate & $>1.45$ & 0.846 & 0.000 & $91.3 \%$ & $29.8 \%$ & $37.7 \%$ & $93.6 \%$ & $84.6 \%$ \\
\hline
\end{tabular}

ROC curve analysis to asses serum lactate level as a predictor of mortality revealed that serum lactate level with cut off $>1.45$ had sensitivity of $91.3 \%$, specificity of $29.8 \%$ and NPV of $93.6 \%$ with excellent diagnostic characteristic. ( accuracy rate $84.6 \%$ ) as shown in graph (1) .

\section{ROC Curve}

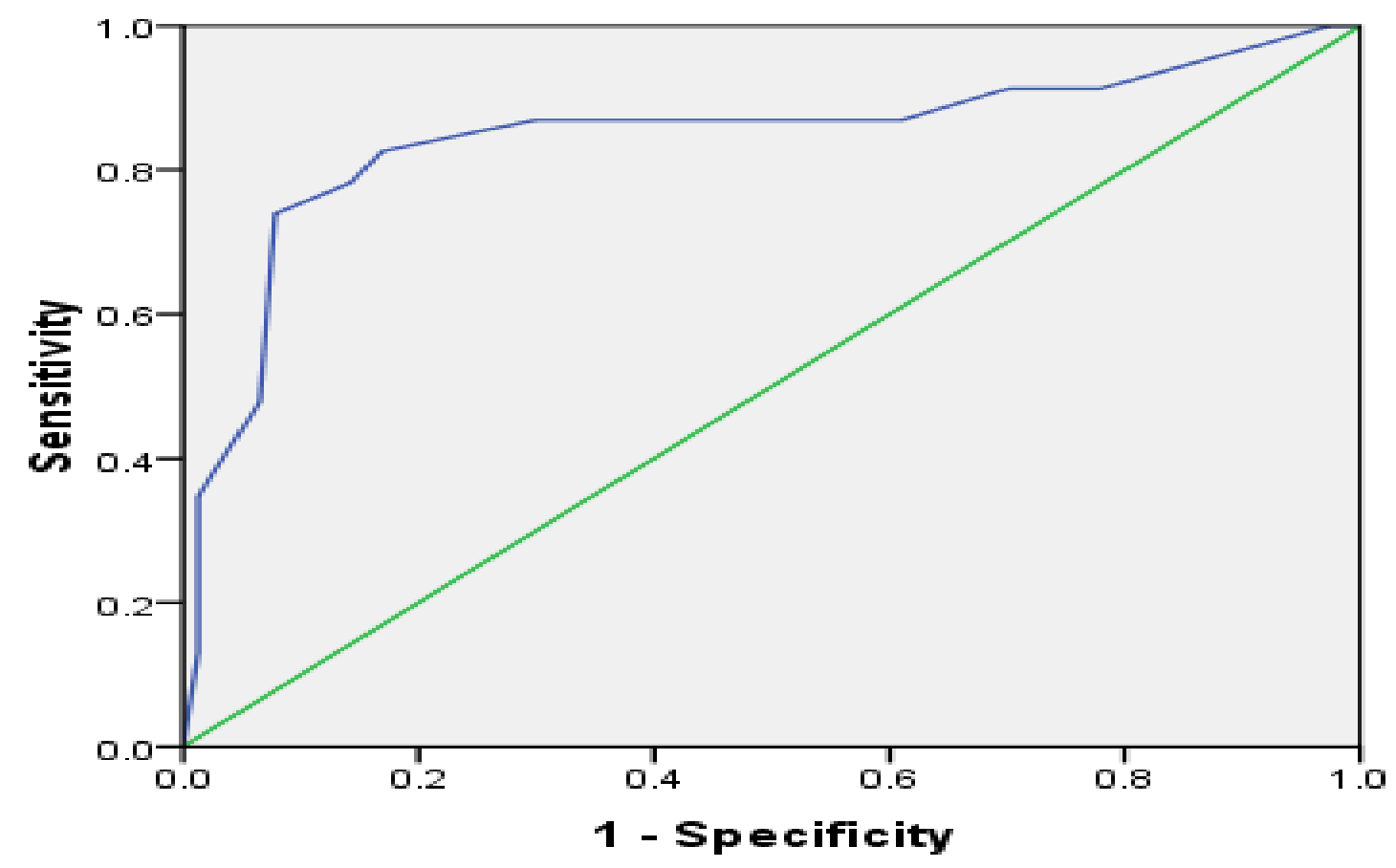

Diagonal segments are produced by ties.

Figure (1): Receiver Operator Characteristic (ROC) Curve of lactate 


\section{DISCUSSION}

The present study found that half of patients $(50 \%)$ fall in the age group pediatrics (1-18 years) and the other half $(50 \%)$ fall in the age group adults (18-60 years) with median age 18.5 years and a mean age of 21.25 years. Female poisoned patients percentage was $59 \%$ are more than male percentage $(41 \%)$ in the study. Haleh et al. (7) investigated the association between acid-base disturbances and mortality in acute poisoning. Of 1167 enrolled patients, 594 were male and median age was 25 years old (range; 13 to 90 years). On the harmony to the present study Cheung $\boldsymbol{e t}$ al. (8) validated the prognostic utility of the initial lactate concentration in a larger, distinct patient population with acute drug overdose. Patients were predominantly female $(56 \%)$ with mean age of 43.1 years.

The present study showed that mode of poisoning mostly suicide $(50 \%)$ the accidently exposed were $35 \%$, the overdose were $12 \%$ and the theraputicaly poisoned (3\%). Erfantalab et al. (3) reported that the value of blood lactate level in prognosis of acute poisoned patients admitted to the medical toxicology intensive care unit (MTICU). The reason for admission was suicide.

In the present study according to $\mathrm{ABG}, 29 \%$ of cases had metabolic acidosis, $22 \%$ have metabolic acidosis and respiratory acidosis, $19 \%$ have normal ph with metabolic acidosis compensated with respiratory alkalosis, $10 \%$ have respiratory acidosis , 9\% were normal, $6 \%$ have metabolic acidosis and respiratory alkalosis, 5\% have respiratory alkalosis, and no patients with metabolic alkalosis. Haleh et al. ${ }^{(7)}$ found that the most common acid-base status was normal pH, mixed metabolic acidosis and respiratory alkalosis (333 cases).

In the present study in case of opioid toxicity, $33.3 \%$ (one of three cases) of patients with acute opioid toxicity are with respiratory acidosis and in case of ethanol toxicity, $0 \%$ ( 0 of 9 patients) of patients with acute ethanol toxicity were with respiratory acidosis. Impaired ventilation due to central nervous system depression is the main cause of respiratory acidosis, a common complication in poisoned patients. Opioids, sedatives, and ethanol are well-known causes of respiratory acidosis ${ }^{(9)}$. Although most metabolic acidosis mortalities were due to narcotics, pesticides including aluminum phosphide (ALP), and antidepressants, the highest rate of metabolic acidosis was due to ALP (100\%), a fumigant pesticide with high mortality rate ${ }^{(10)}$. Metabolic alkalosis has been reported to be the most common acid-base disturbance in ICU patients, but is a rather uncommon acid-base disorder in the poisoned patient ${ }^{(11)}$. Haleh et al. ${ }^{(7)}$ found that opioids accompanied with on-arrival blood gas disturbances including respiratory acidosis were $19 \%$, mixed respiratory and metabolic acidosis were $11 \%$, primary metabolic acidosis were $21 \%$, and primary metabolic alkalosis were $3 \%$.
In the present study, According to lactate level, normal lactate level was detected in $100 \%$ of studied patients with acute lithium, BDZ, clozapex, ethanol, corrosive , and anticonvulsant toxicity and in $75 \%$ of studied patients presented with acute cidophage toxicity. Mild to moderate elevation of lactate level was detected in $100 \%$ of studied patients with acute pergaba, and coingestion of insulin and tegretol toxicity and $50 \%$ of studied patients with acutecarbamate toxicity. High lactate level was detected in $75 \%$ of studied patients with acute Co ,and AL phosphide toxicity . Very high lactate level was detected in $50 \%$ of studied patients with acute(zinc phosphide and salicylate) toxicity, $22.2 \%$ of studied patients with acute (methanol) toxicity. There was statistical very highly significant relationship between the toxic agent and lactate level as $\mathrm{p}$ value was < 0.001 . The role of blood lactate level has been studied as a prognostic factor in drug and chemical poisoning (12). Very few studies have specifically shown the prognostic utility of lactate in the setting of drug poisoning. The association of hyperlactatemia and acidosis with sympathomimetic poisoning likely represents a pathophysiologic response to catecholamines, which may be similar to that during exercise and therapeutic infusion in shock states, and likely reflects the transition from oxidative to partially anaerobic metabolism. Similarly, hyperlactatemia in the setting of opioid poisoning may represent Type A hyperlactatemia due to tissue hypoxia and subsequent anaerobic metabolism. Patients with opioid or sympathomimetic poisoning may have added prognostic utility with a lactate concentration sent as part of the routine ED workup to aid medical decision making ${ }^{(13)}$. Cheung et al. ${ }^{(8)}$ found that the highest utility for prediction of fatality by the initial lactate concentration occurred in these drug classes: salicylates, sympathomimetics, acetaminophen, opioids, digoxin, anti-convulsants and lactate concentration had lowest utility for beta adrenergic antagonists and Ca-channel blockers, diuretics, and ACE inhibitors.

In the present study according to the site of admission the studied patients with normal lactate level, $76.7 \%$ of themwere admitted at in-patient, $19 \%$ of themwere admitted to ICU, $4.3 \%$ of them were admitted to ED. The studied patients with mild to moderate elevation of lactate level, $58.3 \%$ of themwere admitted at in-patient and $41.7 \%$ of themwere admitted to ICU. The studied patients with high elevation of lactate level $95.2 \%$ of them were admitted to ICU and $4.8 \%$ of themwere admitted to in-patient. The studied patients with very high elevation of lactate level, 75\% of them were admitted to ICU, $25 \%$ of them were admitted at in-patient. There was statistical very highly significant relationship between the type of acid base disturbances and outcome as $\mathrm{p}$ value was $<0.001$. Although the direct role of acidosis in clinical outcome 
remains uncertain, it has been shown as a predictor of poor outcome in critically ill patients ${ }^{(14)}$.

Haleh et al. ${ }^{(7)}$ stated that 200 patients $(17.1 \%)$ were admitted to ICU from one thousand one hundred and seventy total patients in the study. In contrast, Nichol et al. ${ }^{(15)}$ found that blood lactate level has been reported to be a poor prognostic factor predicting death in hospital and ICU-admitted patients.

In the present study according to the the type of acid base disturbances and out come, $47.8 \%$ of the dead patients in the study suffered from metabolic acidosis with respiratory acidosis, $30.4 \%$ of them were with metabolic acidosis, $13 \%$ of them were with respiratory acidosis and $8.7 \%$ of them were with metabolic acidosis with respiratory alkalosis. There was statistically highly significant relationship between the type of acid base disturbances and outcome as $\mathrm{p}$ value was $<0.01$. Soltaninejad $\boldsymbol{e t}$ al. ${ }^{(16)}$ demonstrated that blood pressure, pulse rate, blood $\mathrm{pH}$, and serum bicarbonate level were significantly different between survivors and non-survivors groups. Mortality rate has been reported to be less than $2 \%$ and is generally attributed to self-poisoning in developing countries ${ }^{(17)}$. This rate in acute poisoning has been reported to be less than $1.1 \%$ in western world ${ }^{(18)}$. Hamdi et al. ${ }^{(19)}$ investigated the association between acid-base disturbances and mortality in acute poisoning. They concluded that on-arrival acid-base status predicts survival and can be used in detection ofprognosis of the poisoned patients. Haleh et al. (7) found that 98 patients died $(74.5 \%$ of them were male). Concerning magnitude of acid-base disturbances, the following statuses were significantly related to death: severe respiratory acidosis, severe metabolic acidosis, and marked respiratory alkalosis.

In the present study according to the GCS and out come, $26.1 \%$ of the dead patients were with GCS $3,17.4 \%$ of them were with GCS $4,13 \%$ of them were with GCS 15 and $8.7 \%$ of them were with GCS 5, 7, 11,12 , and 13. There was statistical very highly significant relationship between GCS and outcome as $\mathrm{p}$ value was $<0.001$.

The present study showed very highly significant difference between lactate level in died patients and survivors as the mean in died was 7.98 $\mathrm{mmol} / \mathrm{L}$ while in survivors was $2.65 \mathrm{mmol} / \mathrm{L}$. Manini et al. (4) reported that the initial ED lactate concentration has prognostic utility for in-hospital mortality from acute drug poisoning. The optimal lactate cutpoint was $3.0 \mathrm{mmol} / \mathrm{L}$ (84\% sensitivity, $75 \%$ specificity), which conferred a 15.8-fold increase in odds of fatality. Shively et al. ${ }^{(20)}$ found an association between the initial ED lactate concentration and severe outcome in patients with acute salicylate poisoning. In critically ill patients, lactate guided therapy and early lactate clearance has been associated with improved outcome. Early lactate clearance may indicate a reduction in overall injury caused by prolonged hypoperfusion or hypoxia. Threshold lactate concentrations may aid providers in decisions to administer more aggressive extracorporeal therapies or antidotes, and may provide better ability to gauge response to therapeutic interventions. Additionally, multi-biomarker approaches may have incremental value over lactate alone for the assessment of acute drug overdose ${ }^{(\mathbf{2 1})}$.

In the present study, serum lactate level had sensitivity of $91.3 \%$ as 20 patients had abnormal serum lactate level among 23 died, while specificity was $29.8 \%$ as 44 patients had normal serum lactate level among 77 survivors. Positive predictive value ( PPV) of lactate was $37.7 \%$ as 20 patients died from total 53 had abnormal lactate level and negative predictive value (NPV) was $93.6 \%$ as 44 patients survived from total 47 had normal lactate level. Erickson et al. (22) recommended that the routine approach to a patient with an unknown overdose should include measuring serum lactate concentration. Because if the initial lactate concentration can predict mortality early in the patient's course, it may be crucial for the direction of patient care. Given that the optimal lactate cutpoint for fatality is $5.0 \mathrm{mmol} / \mathrm{L}$, this threshold identifies patients for whom ICU admission is warranted or should at least be seriously considered, unless application of a drug-specific cutpoint is possible. Furthermore, a lactate concentration $<2.0 \mathrm{mmol} / \mathrm{L}$ has outstanding negative predictive value for mortality and may identify a low risk subset of patients for medical clearance in the absence of a clinical toxidrome or other concerning clinical findings. Given the drugspecific prognostic utility for lactate, this biomarker should be interpreted with the aid of medical toxicology consultation. Conversely, lactate does not appear to be useful for medical decision making for patients with isolated drug poisoning from a diuretic, or ACE inhibitor. Cheung et al. ${ }^{(8)}$ found that the AUC for prediction of fatality was 0.85 . The optimal lactate concentration cutpoint for fatality was $5.0 \mathrm{mmol} / \mathrm{L}$, which was $70.8 \%$ sensitive and $94.7 \%$ specificity. The optimal cutpoint for the occurrence of both primary and secondary outcomes combined (i.e., shock or death) was $2.7 \mathrm{mmol} / \mathrm{L}$. An initial lactate concentration of $7.5 \mathrm{mmol} / \mathrm{L}$ or greater had $23.8 \%$ positive predictive value and $<2.0 \mathrm{mmol} / \mathrm{L}$ had $99.5 \%$ negative predictive value.

Receiver operating characteristic (ROC) curve analysis was used to asses serum lactate level as a predictor of mortality and revealed that serum lactate level with cut off $>1.45$ had sensitivity of $91.3 \%$, specifity of $89.4 \%$ and NPV $93.6 \%$ with excellent diagnostic characteristic (accuracy rate 84.6\%). Erfantalab et al. (3) showed that the results of ROC analysis and relative risk for death with regard to blood lactate levels at 4 to 24 hours post-ingestion. An area under the receiver operating characteristic (ROC) curve for the first 2-hour post-ingestion was 0.364. A curve was constructed as blood lactate levels versus time post-ingestion based on ROC analysis data, and a 
line was drawn to separate the patients who are at risk of death from those who are not. The curve plots the line of best fit connecting the lactate level of 5.4 $\mathrm{mmol} / \mathrm{L}$ at 4 hours and $2.8 \mathrm{mmol} / \mathrm{L}$ at 24 hours postingestion. The levels above the line were used to predict the likelihood of death. They concluded that evaluation of blood lactate level could be used as an index of severity of poisoning and for decision-making about treatment provided in acute poisoning. Cheung et $\boldsymbol{a l} .{ }^{\left({ }^{(8)}\right.}$ demonstrated that initial lactate concentration is a useful biomarker for early clinical decisionmaking in ED patients with acute drug overdose.

\section{CONCLUSION}

Blood gas analysis not only helps in diagnosis, but also in detection of prognosis, and in recognition of patients who need intensive care. The initial lactate level have prognostic utility for detection of fatality from some acute toxicity, and might be used as a biomarker that can aid early decision-making. The highest fatality rate among the acid base disturbances was in metabolic acidosis with respiratory acidosis and then metabolic acidosis. Serum lactate level was a predictor of mortality with excellent diagnostic characteristic, and the cut off of serum lactate level was $>1.45$

\section{REFERENCES}

1. Paasma R, Hovda K, Hassanian M et al. (2012): Risk factors related to poor outcome after methanol poisoning and the relation between outcome and antidotes--a multicenter study. Clinical Toxicology, 50: 823-831.

2. Consoli A, Nurjhan $\mathrm{N}$, Reilly $\mathrm{J}$ et al. (1990): Contribution of liver and skeletal muscle to alanine and lactate metabolism in humans. American Journal of Physiology, 259: 677-684.

3. Erfantalab $\mathbf{P}$, Soltaninejad $\mathrm{K}$, Shadnia $\mathrm{S}$ et al. (2017): Trend of blood lactate level in acute aluminum phosphide poisoning. World Journal of Emergency Medicine, 8 (2): 116-120.

4. Manini A, Kumar A, Olsen D et al. (2015): Utility of serum lactate to predict drug-overdose fatality. Clinical Toxicology, 48 (7): 730-736.

5. Lars W, Julie M, Jonathan C et al. (2013): Etiology and therapeutic approach to elevated lactate levels. Mayo Foundation for Medical Education and Research Mayo Clinic and Proceedings, 88 (10): 112-118.

6. Randy C, Robert S, David V et al. (2018): Prognostic utility of initial lactate in patients with acute drug overdose: A Validation Cohort. Annals of Emergency Medicine, 72: 16-23.

7. Haleh H, Hossein H, Amir $\mathrm{H}$ et al. (2016): Acid-base disturbances in acute poisoning and their association with survival. Journal of Critical Care, 35: 84-89.
8. Cheung R, Hoffman R, Vlahov D et al. (2018): Prognostic utility of initial lactate in patients with acute drug overdose: A Validation Cohort. Annals of Emergency Medicine, 72 (1): 16-23.

9. Shannon M, Borron S, Burns M (2007): Respiratory acidosis. In :Haddad and Winchester's Clinical Management of Poisoning and Drug Overdose. $4^{\text {th }}$ edition. Saunders/Elsevier. Chapter 3, Pp: 112-113.

10. Hassanian-Moghaddam H, Pajoumand A (2007): Two years epidemiological survey of aluminium phosphide poisoning in Tehran. Iranian J. Toxicol., 1: 35-39.

11. Heyerdahl F, Bjornas M, Hovda K (2008): Acute poisonings treated in hospitals in Oslo: a one-year prospective study (II): clinical outcome. Clinical Toxicology, 46: 42-49.

12. Rishu A, Khan R, Al-Dorzi H (2013): Even mild hyperlactatemia is associated with increased mortality in critically ill patients. Critical Care, 17: 197-199.

13. Barth E, Albuszies G, Baumgart K (2007): Glucose metabolism and catecholamines. Critical Care Medicine, 35: 508-518.

14. Warner M, Chen L, Makuc D et al. (2011): Drug poisoning deaths in the United States, 1980-2008. NCHS Data Brief, 81: 1-8.

15. Nichol A, Egi M, Pettila V et al. (2010): Relative hyperlactatemia and hospital mortality in critically ill patients: a retrospective multi-centre study. Critical Care, 14: 25-35.

16. Soltaninejad K, Beyranvand M, Momenzadeh S et al. (2012): Electrocardiographic findings and cardiac manifestations in acute aluminum phosphide poisoning. Journal of Forensic and Legal Medicine, 19 (5): 291-293.

17. Cook R, Allcock R, Johnston M (2008): Selfpoisoning: current trends and practice in a U.K. teaching hospital. Clinical medicine (London, England), 8: 37-40.

18. Boshehri B, Salimi S, Ranjbar S (2012): Mortality from acute poisoning in urmia: A three-year retrospective study. Iran Red Crescent Med J., 14: 838839.

19. Hamdi H, Hassanian M, Hamdi A et al. (2016): Acid-base disturbances in acute poisoning and their association with survival. Journal of Critical Care, 35: 84-89.

20. Shively R, Hoffman R, Manini A (2017): Acute salicylate poisoning: risk factors for severe outcome. Clinical Toxicology, 55 (3): 175-180.

21. Jansen T, van Bommel J, Schoonderbeek F (2010): Early lactate-guided therapy in intensive care unit patients: a multicenter, open-label randomized controlled trial. American Journal of Respiratory Critical Care Medicine, 182 (6): 752-761.

22. Erickson T, Thompson T, Lu J (2007): The approach to the patient with an unknown overdose. Emergency Medicine Clinics of North America, 25: 249-281. 